\title{
Textural characteristics and impurity content of meteoric and marine ice in the Ronne Ice Shelf, Antarctica
}

\author{
Hajo Eicken, Hans Oerter, Heinz Miller, \\ Alfred-Wegener-Institut für Polar- und Meeresforschung, D-27515 Bremerhaven, Germany \\ WOLFGANG GRAF, \\ GSF-Forschungszentrum für Umwelt und Gesundheit München, D-85758 Neuherberg, Germany \\ JOSEF KIPFSTUHL \\ Alfred-Wegener-Institut für Polar- und Meeresforschung, D-27515 Bremerhaven, Germany
}

\begin{abstract}
The texture and physical properties of an ice core, recovered to $215 \mathrm{~m}$ depth from the Ronne Ice Shelf, Antarctica, have been studied with regard to formation and transformation of the ice. At a depth of $152.8 \mathrm{~m}$, a sharp discontinuity marks the transition between meteoric ice accumulated from above and marine ice accreted from below, as testified by electrolytical conductivity and stable-isotope measurements as well as geophysical field surveys. Automated image analysis of thin sections indicates that the decrease in grain-boundary density and the increase in grain cross-sectional area with depth is commensurate with though not necessarily caused by thermodynamically driven grain growth down to $120 \mathrm{~m}$ depth, corresponding to a vertical strain of roughly $65 \%$ as computed with a simple temperature-history, particle-path model. The observed increase of grain-boundary density (i.e. a decrease of grain-size) with age in the marine ice is in part explained by the thermal history of this layer. Sediment inclusions at the top of the marine-ice layer affect the observed grain-boundary density profile by inhibiting grain growth and dynamic recrystallization. This may allow some conclusions on the role of temperature, particulate inclusions, stress and strain rate in controlling the grain-size evolution of deforming ice, supplementing earlier laboratory experiments conducted at much shorter time-scales. Salinities $(0.026 \% \circ)$, brine volumes $(0.09-0.2 \% 0)$ and solid-salt concentrations have been computed from electrolytical conductivity measurements (mean of $51.0 \times 10^{-6} \mathrm{~S} \mathrm{~cm}^{-1}$ ) for the marine ice. An assessment of salt incorporation and desalination rates shows that these low salinities can at present only be explained by a unique densification mechanism of under-water ice crystals at the base of the ice shelf.
\end{abstract}

\section{INTRODUCTION}

Ice shelves as floating extensions of the Antarctic ice sheet account for a major fraction of the Antarctic coastline. The two largest ice shelves, the Filchner-Ronne Ice Shelf and the Ross Ice Shelf cover respective areas of approximately $0.53 \times 10^{6}$ and $0.54 \times 10^{6} \mathrm{~km}^{2}$ (Drewry, 1983). As sensitive components of the Antarctic ice sheet, ice shelves play an important role in the global climate system, not least because of their high albedo and their significance in the hydrological cycle. Furthermore, exchange processes occurring at the bottom of ice shelves have been demonstrated to be important both for the formation of Southern Ocean water masses and for the coupling between ice sheets and the world ocean (Hellmer and Olbers, 1991; Jenkins and Doake, 1991; Nicholls and others, 1991).

In order to learn more about the structure and the dynamics of Antarctic ice shelves, research in the past two decades has focused on the Ross Ice Shelf and on the
Filchner-Ronne Ice Shelf. For the latter, extensive data on ice velocities (e.g. Ritter and Karsten, 1991), ice thickness (e.g. Thyssen, 1988; Vaughan and others, 1991) and surface accumulation (Graf and others, 1991) have been gathered and incorporated into numerical models of ice-shelf flow (e.g. Determann, 1991; Jenkins and Doake, 1991). Analysis of electromagnetic reflection profiling data has established the two-fold structure of the Ronne Ice Shelf, with a layer of saline ice underlying an internal discontinuity in the central part of the ice shelf (Thyssen, 1988). Drill holes through its entire thickness have provided further indirect evidence of ice accreting from below (Engelhardt and Determann, 1987; Nicholls and others, 1991). Detailed topographic studies have confirmed bottom accumulation in the central Ronne Ice Shelf over a distance of $350 \mathrm{~km}$, starting at approximately $80^{\circ} \mathrm{S}$ between Berkner Island and Henry Ice Rise (Thyssen, 1988). To obtain more substantial information on the nature of the accreted ice and its mode of formation, a deep core (B13) was drilled by a group from 


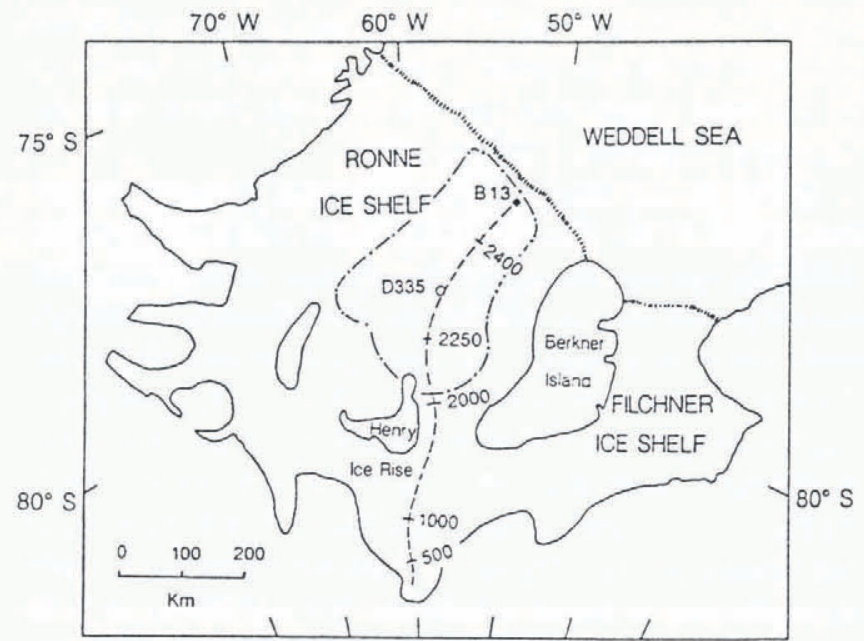

Fig. 1. Map of the Filchner-Ronne Ice Shelf. The location of the B13 drilling site is shown along with the corresponding flowline. The dash-stippled line marks the occurrence of marine ice under the ice shelf. Numbers along the flowline indicate approximate travel times of ice from the grounding line in years.

the Alfred Wegener Institute in 1989-90 (Fig. 1; Oerter and others, 1992). In this paper we report on the textural stratigraphy and the properties of this ice. From the data available, we will attempt to gain insight into the deposition and transformation of ice in the Ronne Ice Shelf both from above and below.

\section{MATERIAL AND METHODS}

\subsection{Field-site measurements}

During the cruise ANT VIII/5 of RV Polarstern in 198990 , a core was recovered from a hole drilled mechanically to a depth of $215 \mathrm{~m}$ in the Ronne Ice Shelf at $76^{\circ} 58^{\prime} \mathrm{S}$ $52^{\circ} 16^{\prime} \mathrm{W}$, located $30 \mathrm{~km}$ away from the ice-shelf front (site B13, Fig. 1). The location was chosen based on earlier electromagnetic reflection (EMR) profiling by a group from the University of Münster which indicated the ice was laterally homogeneous in the vicinity and upstream of the site (Blindow, 1990). Based on the EMR data, the ice thickness was determined as about $240 \mathrm{~m}$ with a marked discontinuity at roughly $155 \mathrm{~m}$ (Blindow, 1990). The site was located within the peripheral ice-shelf zone with vigorous bottom ablation.

Drilling was conducted with a mechanical rig providing a core of approximately $72 \mathrm{~mm}$ diameter. Core processing at the site comprised stratigraphic description and photodocumentation, continuous measurements of d.c. conductivity and density measurements by weighing cylindrical sections (Oerter and others, 1992). A temperature log was obtained over a period of $2 \mathrm{~d}, 3$ weeks after the start of drilling, by allowing a thermistor sensor to attain thermal equilibrium at positions spaced a few metres apart.

\subsection{Laboratory measurements}

Apart from the visual core stratigraphy, 31 horizontal thin sections at approximately $10 \mathrm{~m}$ intervals have been prepared (plus eight at close spacing and a further 15 vertical sections). For these sections, crystallographic caxis orientations have been determined with a universal stage. The thin sections have also been recorded with a video camera for an evaluation of grain-size and shape, employing image-processing techniques as described by Eicken (1993). In brief, two images ( $50 \mathrm{~mm}$ wide) of a thin section placed between crossed polarizers at different, pre-defined orientations are digitized. With the aid of non-linear filtering routines, signals resulting from pores are removed from the images. After union of the two frames, a Sobel filter which enhances regions of high spatial contrast is applied. Following binarization about a threshold value, the image is segmented into grains and grain boundaries to determine size and distribution of grains. For comparison with manual measurements (e.g. Gow, 1969; Lipenkov and others, 1989), the average cross-sectional area, $A_{\text {mean }}$, has been determined by counting the number of grains cut in individual thin sections of a known area. For the four upper thin sections taken within the firn layer, where pores account for a significant part of the thin section, $A_{\text {mean }}$ has been corrected based on the firn density at the respective depth.

Electrolytical conductivities have been determined on melted cuttings over the entire length of the core, with values integrated over approximately $0.8 \mathrm{~m}$ depth for each core segment. Measurements were taken with a WTW LF 191 conductivity probe at temperatures between $10^{\circ}$ and $20^{\circ} \mathrm{C}$ with conductivities corrected to a reference temperature of $25^{\circ} \mathrm{C}$. Concentrations of major ions, ${ }^{2} \mathrm{H}$ and ${ }^{18} \mathrm{O}$ have been determined at selected depth levels (Oerter and others, 1992).

\section{RESULTS: TEXTURE AND PHYSICAL PROPERTIES OF THE B13 CORE}

\subsection{General stratigraphy}

The upper $150 \mathrm{~m}$ of the core displays the typical sequence of snow grading into firn with a transition to bubbly ice at depth. Below an undulating discontinuity extending over $10-20 \mathrm{~mm}$ depth at $152.8 \mathrm{~m}$, the core takes on a completely different appearance. The ice is transparent due to the lack of gas-filled pores. At depths between $152.8 \mathrm{~m}$ to approximately $159 \mathrm{~m}$ numerous spherical aggregates (few millimetres diameter) of particulate inclusions (mostly clay and silt size fractions (personal communication from R. Petschick, 1992)) occur in strings or layers with few centimetres vertical separation throughout the ice. Below $159 \mathrm{~m}$ these aggregations decrease in number. Closer inspection of the ice reveals a faintly visible network of liquid inclusions, mostly confined to grain boundaries and triple-grain junctions. Scanning electron microscope (SEM) analysis of samples from four depths also demonstrates the intergranular distribution of salts within the ice (Moore and others, 1994). As proposed in previous studies (Engelhardt and Determann, 1987; Thyssen, 1988) and according to stable-isotope measurements (Oerter and others, 1992) as well as other evidence discussed below, the discontinuity marks the transition from meteoric ice deposited as 
snow at the upper surface to marine ice accreted from below.

\section{2. Density profile of firn and ice}

The depth-density profile of the core appears linear from 10 to $60 \mathrm{~m}$ depth (Fig. 2a). Below that, the curve asymptotically approaches the maximum theoretical density of ice. The scatter below $75 \mathrm{~m}$ depth is due to the poorer quality of the core segments rather than representing true variability. From the core stratigraphy, it appears that the inflection in the profile at $37 \mathrm{~m}$ depth is due to a combination of decreasing core quality and the appearance of ice lenses. The maximum density attainable through physical re-arrangement of grains (c. $550 \mathrm{~kg} \mathrm{~m}^{-3}$; Paterson, 1981 , p. 10) is surpassed at a depth of approximately $12 \mathrm{~m}$. The transition from firn to ice, as defined by pore close-off density of $830 \mathrm{~kg} \mathrm{~m}^{-3}$, occurs at roughly $50 \mathrm{~m}$ depth. For accumulation rates varying between 204 and $154 \mathrm{~kg} \mathrm{~m}^{-2} \mathrm{a}^{-1}$ and $10 \mathrm{~m}$ temperatures
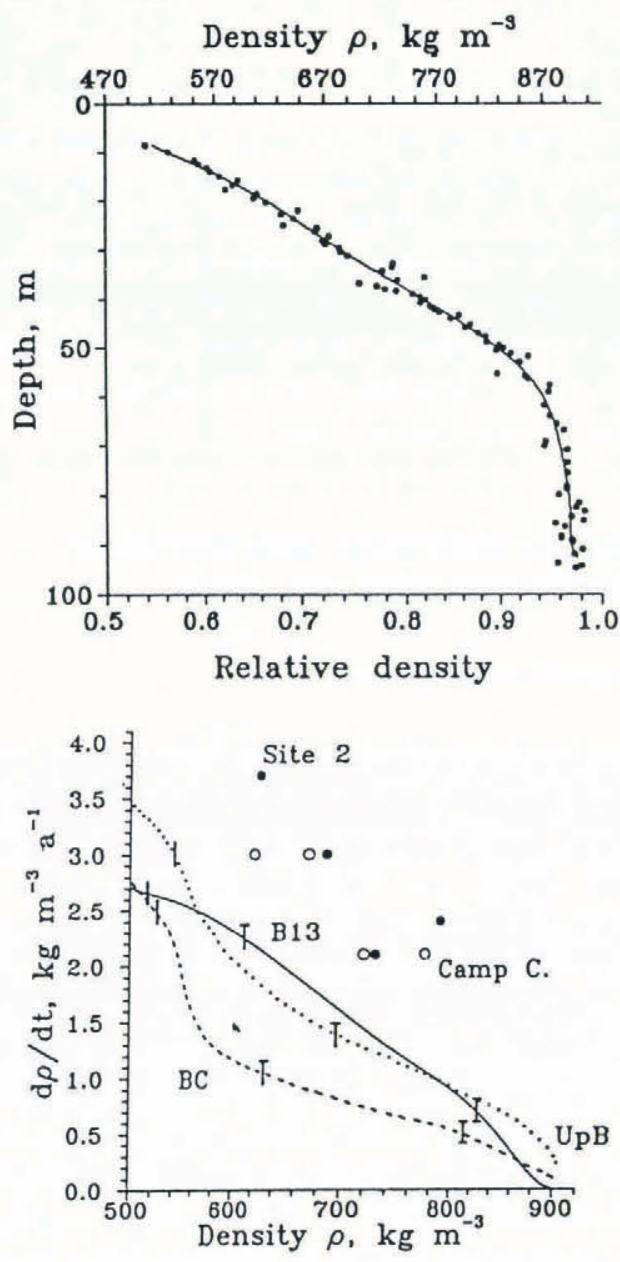

Fig. 2. a. Depth-density profile of the upper $100 \mathrm{~m}$ of the core. Solid line is an eighth-order polynomial fit to the data. b. Densification rate vs density of ice and firn at B13 based on the computed age-depth function (solid line). Dashed and stippled lines from Alley and Bentley (1988) as measured at sites $B C$ and $U p B$ on the Siple Coast, Antarctica. The bars mark the positions of the $10 \mathrm{~m}$ (simple bar), $25 \mathrm{~m}$ (top cross-bar) and $50 \mathrm{~m}$ (top and bottom cross-bar) depth levels. Dots computed from Greenland data given by Gow (1968). between $-23.5^{\circ}$ and $-26.1^{\circ} \mathrm{C}$ at the site and up to $200 \mathrm{~km}$ upstream (Graf and others, 1991), this value is similar to results from comparable sites in both the Arctic and the Antarctic (Paterson, 1981, p. 15).

Based on the ice-shelf dynamics data gathered in the framework of the Filchner-Ronne Ice Shelf Programme (FRISP), we can assess the density-age relationship and potential strain-rate effects on densification through application of a simple ice-shelf flow model (Thomas, 1973; for details see section 4.1). The model compares quite well with the ${ }^{18} \mathrm{O}$ and ${ }^{2} \mathrm{H}$ record for this and other shallow drill sites in the vicinity (Graf and others, 1991). As shown in Figure $2 b$, the densification rate derived from the computed age-depth relation decreases in a nearlinear fashion at densities between 500 and $900 \mathrm{~kg} \mathrm{~m}^{-3}$. At the righthand end of the curve, ice layers are approximately 300 years old and have experienced roughly $40 \%$ vertical compressive strain. In comparison, data from Alley and Bentley (1988) collected at two sites (UpB and BC) on the Siple Coast in Antarctica, with accumulation rates of 79 and $82 \mathrm{~kg} \mathrm{~m}^{-2} \mathrm{a}^{-1}$ and $10 \mathrm{~m}$ temperatures of $-26.4^{\circ}$ and $-26.5^{\circ} \mathrm{C}$ are in the same range or below the $\mathrm{B} 13$ data. The discrepancy between $\mathrm{BC}$ and $\mathrm{B} 13$ values is most likely due to lower $10 \mathrm{~m}$ temperatures and accumulation rates at the Siple Coast sites, whereas the $\mathrm{UpB}$ densification rates are thought to be anomalously high due to the softening effect of large deviatoric stresses in the ice stream (Alley and Bentley, 1988). The dependence of $\mathrm{d} \rho / \mathrm{d} t$ on accumulation rate should also explain the factor 1.5-2 difference in densification rates between B13 and sites in Greenland (Gow, 1968) with values of $400 \mathrm{~kg} \mathrm{~m}^{-2} \mathrm{a}^{-1}$ (site 2) and $340 \mathrm{~kg} \mathrm{~m}^{-2} \mathrm{a}^{-1}$ (Camp Century), yet similar temperatures $\left(-24^{\circ} \mathrm{C}\right)$. Also, taking into account the slight temperature increase with depth at site $\mathrm{B} 13\left(-21^{\circ} \mathrm{C}\right.$ at $50 \mathrm{~m}$ depth), it appears from Figure $2 \mathrm{~b}$ that densification rates in the Ronne Ice Shelf with vertical strain rates of $1 \times 10^{-3}$ to $2 \times 10^{-3} \mathrm{a}^{-1}$ are not enhanced as compared to Siple Coast and Greenland sites.

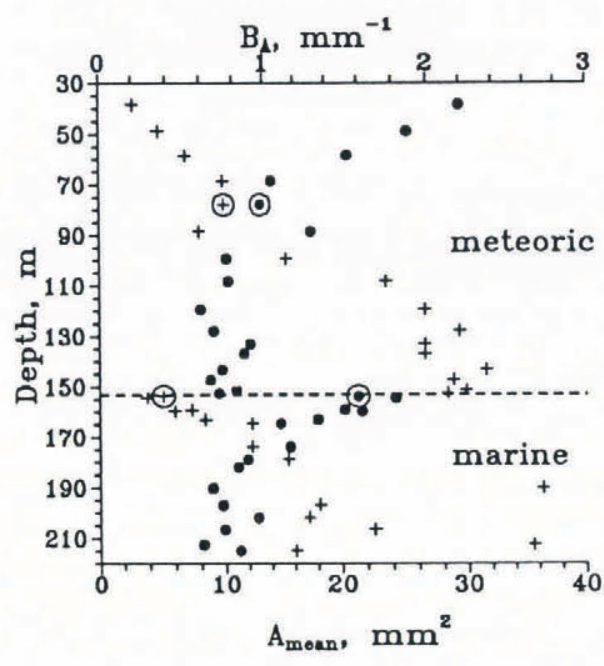

Fig. 3. Profile of grain-boundary density $B_{\mathrm{A}}$ with depth as determined on thin sections employing automated imageanalysis techniques (closed circles). Also shown is the mean cross-sectional area of grains as determined manually (crosses). Open circles mark layers of roughly equal cumulative strain (see section 4.3). 


\subsection{Thin-section studies of core texture and fabric}

Horizontal and vertical thin sections have been prepared at regular depth intervals excepting the top $38 \mathrm{~m}$ of firn. With the aid of automated image-analysis techniques (for details see Eicken, 1993), the grain-boundary density $B_{\mathrm{A}}$ has been determined as a key textural parameter. $B_{\mathrm{A}}$ is defined as the length of grain boundaries per unit area. It can be of use in describing the gradual minimization of free boundary energy as a driving force for grain growth. Generally, $B_{\mathrm{A}}$ scales inversely with mean grain-size, assuming grains of convex outlines. The depth profile of
$B_{\mathrm{A}}$ is shown in Figure 3. The grain-boundary density decreases by a factor of 3 with depth within the meteoric ice layer (thin-section photographs in Figures $4 a$ and 5a). Intragranular pores (distinct in Figure 5a) appear at a depth below approximately $58 \mathrm{~m}$, i.e. close to the firn-ice transition. At depths below roughly $95 \mathrm{~m}$, grains of meteoric ice deviate from the fully convex, isometric shape. Furthermore, crystals begin to exhibit wavy extinction and polygonization.

For comparison, Figure 3 also shows the depth distribution of mean grain cross-sections, $A_{\text {mean }}$, determined manually. The meteoric ice layer is characterized

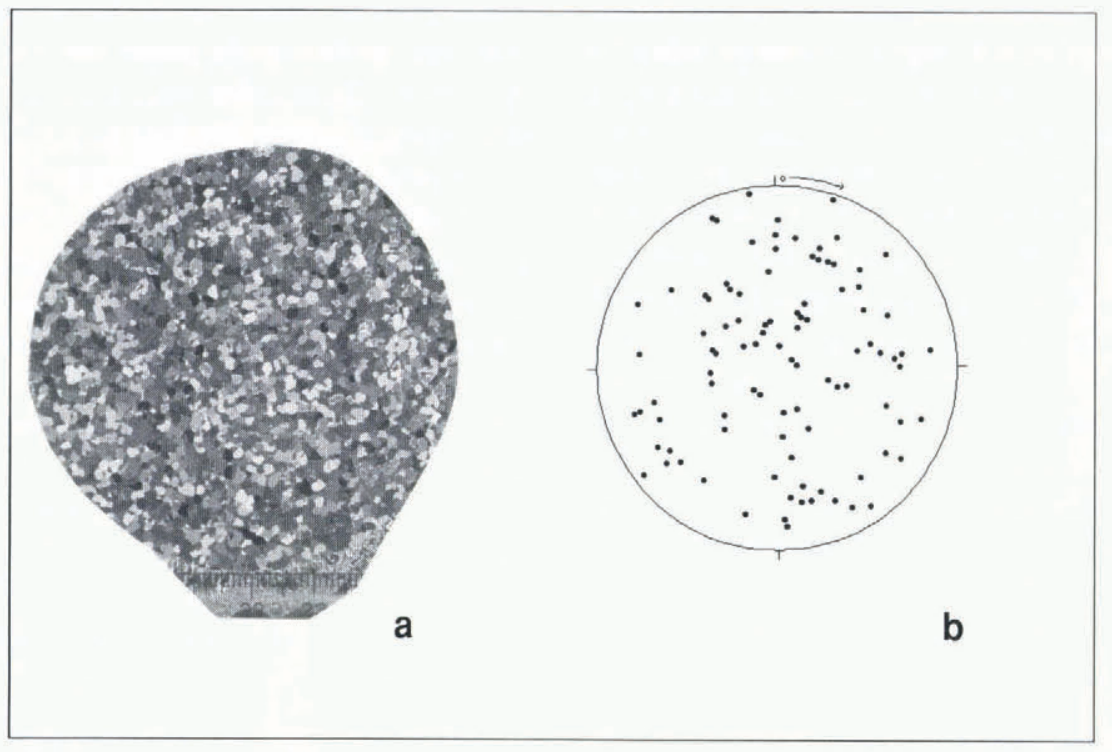

Fig. 4.a. Photograph of a horizontal thin section of meteoric ice at $38.44 \mathrm{~m}$ depth taken between crossed polarizers (mm scale at the side). Pores faintly visible as black dots at grain junctions. b. c-axis fabric diagram (Schmidt-net plot) of the sample shown in Figure $4 a$ (98 crystals measured).

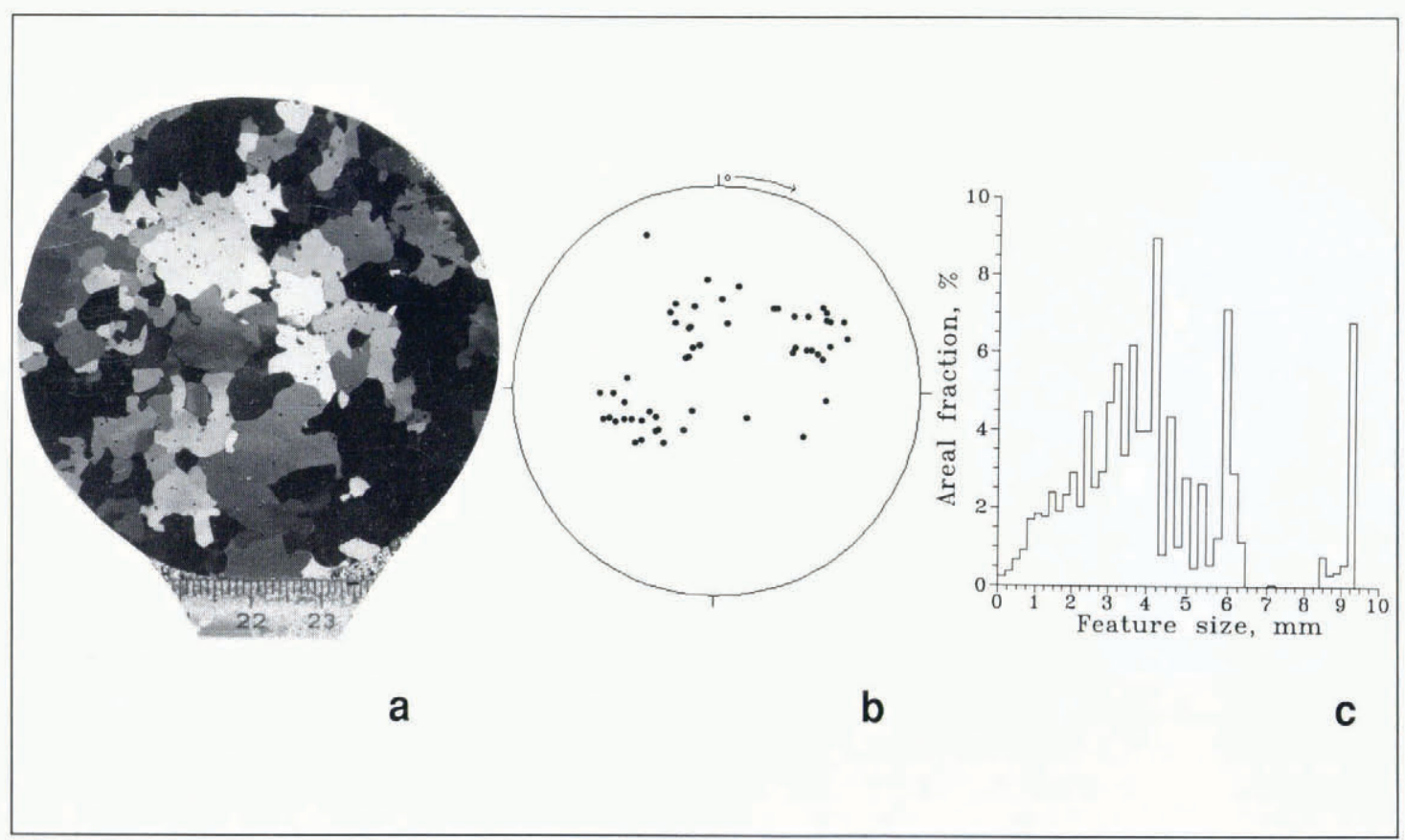

Fig. 5. a. Photograph of a horizontal thin section of meteoric ice at $136.95 \mathrm{~m}$ depth taken between crossed polarizers (mm scale at the side). Pores visible within grains. b. c-axis fabric diagram (Schmidt-net plot) of the sample shown in Figure $5 a$ ( 55 crystals measured). c. Size distribution of cross-sectional feature or grain areas of the thin section shown in Figure $5 a$, as determined through morphological filtering. 
by a linear increase of grain-size down to $120 \mathrm{~m}$ depth in concordance with observations from ice-sheet cores (Gow, 1969). The grain-sizes reported by Gow range below the values reported here due to the different thermal histories of the ice. Similar grain-sizes have been observed in the Amery Ice Shelf (Wakahama, 1974) and the Ross Ice Shelf (Gow, 1963). In fact, the Amery Ice Shelf core is similar to B13 in many ways regarding texture and $c$-axis fabric, as well as the distribution of liquid and solid impurities. The variability in $A_{\text {mean }}$ compared to grainboundary density is mainly due to the appearance of large grains with indented outlines (Figs $5 \mathrm{a}$ and $7 \mathrm{a}$ ).

The discontinuity between meteoric and marine ice is accompanied by a marked increase in grain-boundary density $B_{\mathrm{A}}$ by a factor of c. 2.5 (Fig. 3), corresponding to a sharp decrease in grain-size with $A_{\text {mean }}$ decreasing by a factor of 6 . At greater depths, $B_{\mathrm{A}}$ decreases to values typical of the lower sections of the meteoric ice layer and $A_{\text {mean }}$ increases again. An examination of vertical thin sections reveals that in the vicinity of the meteoric/ marine-ice discontinuity, grains are commonly arranged into horizontal rows (see also figures shown in Oerter and others (1992)). At the top of the marine ice, most grains are elongated by a factor of $2-5$ in the horizontal direction. At greater depths, this elongation is less distinct or absent; neither is it detectable in the meteoric ice above the transition. Close inspection shows that the strings and sheets of particulate inclusions occurring mostly at depths of $152.8-159 \mathrm{~m}$ are commonly, though not exclusively, concentrated at grain boundaries and triple junctions.

Figures $5 \mathrm{c}$ and $6 \mathrm{c}$ provide information on the size distribution of cross-sectional grain areas, obtained through the application of non-linear, morphological filtering techniques (Eicken, 1993). In brief, this opera- tion can be regarded as a digital sieve, yielding the areal fraction of differently sized grains or grain protrusions. In comparing the two distributions, we note the prevalance of small features or grains in the marine-ice sample, with $55.6 \%$ of the sampled area occupied by features smaller than $2 \mathrm{~mm}$ and $19.0 \%$ smaller than $1 \mathrm{~mm}$. The meteoric ice, on the contrary, is characterized by the dominance of larger grains, with only $14.2 \%$ of the area occupied by features smaller than $2 \mathrm{~mm}$ and $3.9 \%$ smaller than $1 \mathrm{~mm}$.

Both methodical and sampling errors involved in the automated measurements were assessed through replicate measurements on selected thin sections and comparisons with manual measurements were made on thin-section photographs. Thus, methodical errors are estimated at less than $\pm 5 \%$ for $B_{\mathrm{A}}$ larger than $1.5 \mathrm{~mm}^{-1}$, and less than $\pm 10 \%$ for $B_{\mathrm{A}}$ smaller than $1.5 \mathrm{~mm}^{-1}$ (for a more detailed discussion of errors, see Eicken (1993)). Spatial variability of textural parameters on a small scale may pose much more of a problem. Thus, analysis of eight horizontal thin sections spaced roughly $10 \mathrm{~mm}$ apart vertically varied by as much as $25 \%$ in grain-boundary density. Clearly, the issue of vertical and lateral fluctuations in grain-size and fabric should be studied in more detail. However, the general trends studied here are not strongly affected by these small-scale processes.

At the top of the meteoric ice layer and in the firn, $c$ axes of ice crystals are distributed randomly (Fig. 4b). Further down in the meteoric and marine ice, distributions exhibit flattening into a vertical plane (Figs 5-7b). These distributions can be understood as a result of $c$-axis rotation through basal glide for ice under tension (Alley, 1988; Lipenkov and others, 1989). The $c$-axis distributions encountered deeper in the core are most likely a result of the Ronne Ice Shelf's stress state with extension along and little to no compression normal to the flowline,

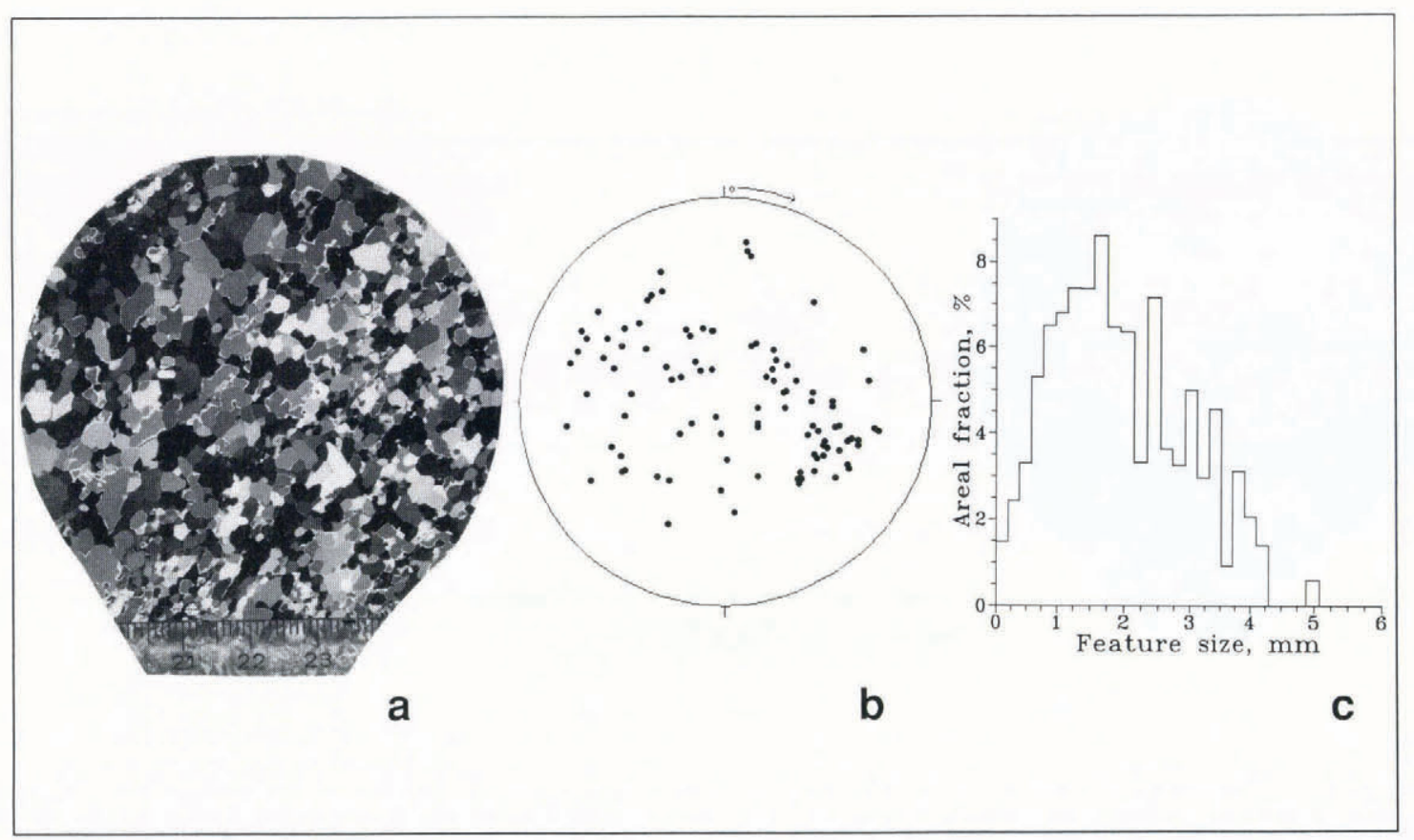

Fig. 6. a. Photograph of a horizontal thin section of marine ice at $153.76 \mathrm{~m}$ depth taken between crossed polarizers (mm scale at the side). b. c-axis fabric diagram (Schmidt-net plot) of the sample shown in Figure $6 a$ (100 crystals measured). c. Size distribution of cross-sectional feature or grain areas of the thin section shown in Figure 6a, as determined through morphological filtering. 


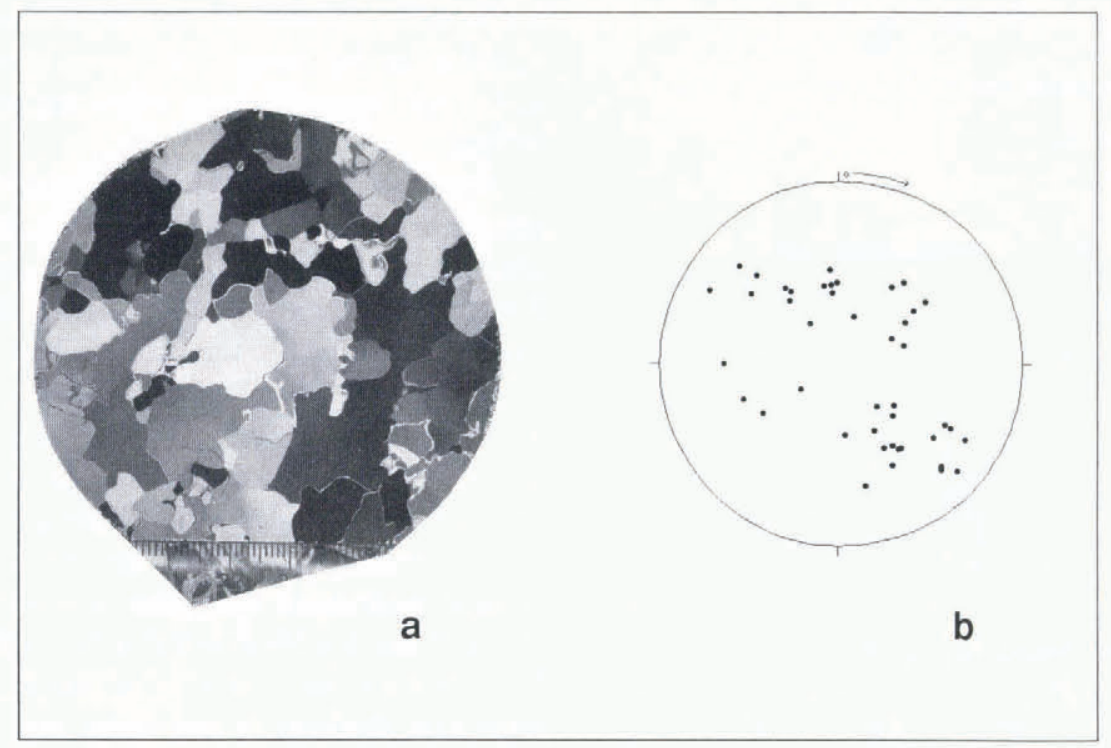

Fig. 7. a. Photograph of a horizontal thin section of marine ice at $206.64 \mathrm{~m}$ depth taken between crossed polarizers (mm scale at the side). b. c-axis fabric diagram (Schmidt-net plot) of the sample shown in Figure $7 a$ (43 crystals measured).

shown by geodetic strain measurements (Ritter and Karsten, 1991). Similar to the clustering of $c$ axes in a vertical plane observed by Lipenkov and others (1989) in the Vostok core and Fujita and others (1987) at Mizuho, $c$ axes rotate away from the tensional axis (here roughly parallel to the flowline). The pole-figure clusters observed deeper in the ice (e.g. Fig. 5b) can in part be explained by sub-parallel alignment of adjacent grains which becomes more pronounced in older ice. Measurements of the crystal-optical misorientation between adjacent grains show that, in the topmost sample (Fig. 4), 25\% of all misorientation angles measured range below $40^{\circ}$ with a median of $61^{\circ}(N=142)$, whereas at $136.95 \mathrm{~m}$ (Fig. 5) $41 \%$ fell below $40^{\circ}$ with a median of $478(N=129)$. In part, clustering may also be due to statistical undersampling in cases where grains become large compared to sample dimensions.

For a single crystal, the shear stress resolved along the basal plane of a crystal is proportional to the geometric or Schmidt factor $S=\cos \theta \sin \theta$ for an angle $\theta$ between the tensional axis and the crystal's $c$ axis. For a polycrystalline aggregate, the average geometric factor is

$$
S_{\mathrm{av}}=\frac{1}{N} \sum_{i=1}^{N}\left(\sin \theta_{\mathrm{i}} \cos \theta_{\mathrm{i}}\right) .
$$

Field data and model results show that $S_{\text {av }}$ decreases with increasing strain (Fujita and others, 1987; Alley, 1988; Lipenkov and others, 1989). For comparison, we have computed $S_{\text {av }}$ by aligning the samples with the long axis of the pole figures (determined through computation of eigenvectors of the distribution) normal to the tensional axis, thus yielding $\theta$. The average geometric factor is plotted against the age jointly with the cumulative vertical strain for the meteoric ice in Figure 8. Age and strain have been obtained from a simple particle-path model outlined further in section 4.1. The general decrease in $S_{\mathrm{av}}$ as strain and age increase is clearly evident, corresponding to the observations of Fujita and others (1987) and Lipenkov and others (1989). Compared to B13, this decrease with strain is accomplished at a similar rate in the Vostok core and at a slightly higher rate in the Mizuho core. Grain-sizes, however, are nearconstant from 150 to $700 \mathrm{~m}$ depth at Mizuho, in contrast to the distinct increase observed in the Ronne Ice Shelf and at Vostok.

\subsection{Electrolytical conductivity of the melted core and brine volumes in the marine-ice layer}

The results of the electrolytical conductivity measure-

- $\mathrm{B}_{\mathrm{A}}$, image-proc. data

$B_{A}$, computation

$+B_{A}$, manual meas.

Strain

* Geometric factor

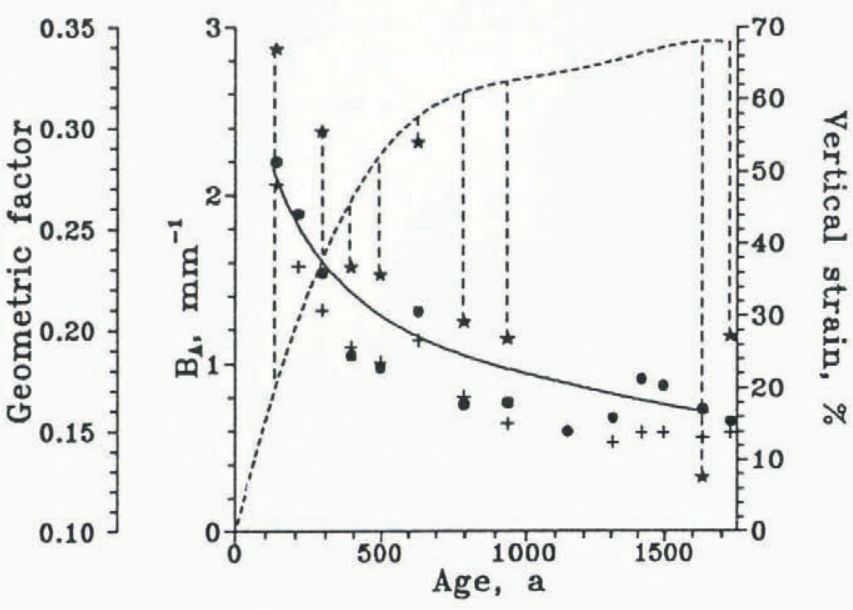

Fig. 8. Geometric factor $S_{\mathrm{av}}$ and grain-boundary density $B_{\mathrm{A}}$ of meteoric ice plotted us age in years. Asterisks represent average geometric (Schmidt) factors of the c-axis distributions. Vertical dashed lines indicate the corresponding cumulative vertical strain ( $\Delta z / z_{0}$, dashed curve). Dots represent automatically measured grain-boundary densities, crosses are converted manual measurements of grain area. The drawn-out line represents the result of a particle-path simulation, assuming grain growth according to an Arrhenius-type relationship (see sections 4.1 and 4.2 for details). 

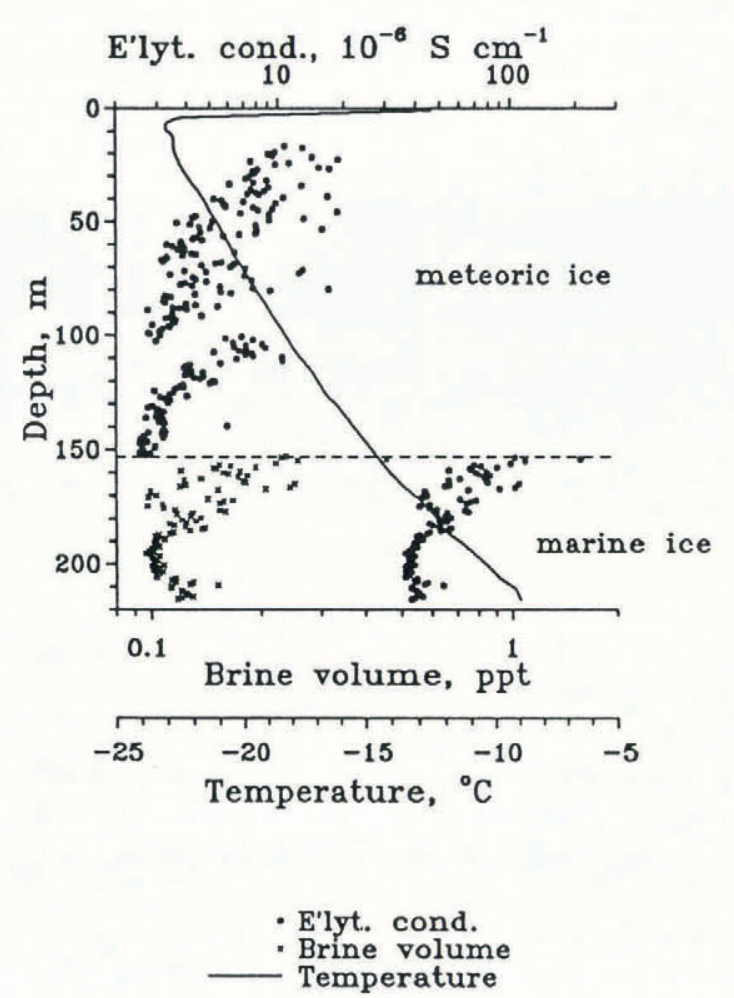

Fig. 9. Depth profile of electrolytical conductivity of melted core sections. Also shown is the temperature profile measured in the drill hole and the brine volume computed from these data according to the equations of Cox and Weeks (1983).

ments are shown in Figure 9. The most distinct feature of the distribution is the sharp transition from meteoric to marine ice with a corresponding increase in conductivity by almost two orders of magnitude. The mean conductivity integrated over the entire depth of the meteoric ice layer amounts to $4.8 \times 10^{-6} \mathrm{~S} \mathrm{~cm}^{-1}(58.3 \%$ standard deviation, as computed for individual, non-integrated measurements), while that of the marine ice with $51.0 \times 10^{-6} \mathrm{~S} \mathrm{~cm}^{-1}$ ( $45.2 \%$ standard deviation) is higher by one order of magnitude. Under the assumption that $\mathrm{Na}^{+}$and $\mathrm{Cl}^{-}$are the major ions contributing to electrolytical conductivities, these conductivities correspond to salinities of roughly $0.002 \%$ and $0.026 \%$, respectively, based on a conversion according to the compilation by Freier (1974) and verified by comparison with ionic concentrations reported by Oerter and others (1992).

Data on salinity, thickness and age of marine-ice occurrences in other locations are listed in Table 1. In contrast to old marine ice found in the Ross Sea sector of the Antarctic (locations 3, 4 and 5 in Table 1) and the Arctic (location 6), the Ronne and Amery Ice Shelves exhibit much lower salinities despite comparable ages. This contrast is stronger than suggested by the low minimum salinities shown for locations 3,5 and 6 in Table 1. In the Hell's Gate Ice Shelf (Antarctica), the small minimum salinities are due to freezing of lowsalinity meltwater (Souchez and others, 1991). In the Ward Hunt Ice Shelf and the Koettlitz Ice Tongue, very few samples show salinities below $1 \%$, attributed to meltwater flushing in the latter case (Gow and Epstein, 1972). Despite their age, these marine-ice layers do not differ significantly in salinity from multi-year sea ice. Salinities of the Amery and Ronne Ice Shelf cores are lower than sea ice by a factor of $20-50$, with strong resemblance between vertical profiles in the two cores. Both display a sharp increase in electrolytical conductivity at the top of the marine-ice layer, with decreasing values below (Morgan, 1972). These close similarities extend to the microstructure and the distribution of particulate impurities.

Temperatures within the marine-ice layer (Fig. 9) are well above the eutectic point of sea water. The fractional volume of brine $V_{\mathrm{B}} / V$ can be computed according to the equations formulated by Cox and Weeks (1983)

$$
\frac{V_{\mathrm{B}}}{V}=\frac{\rho_{\mathrm{i}} S_{\mathrm{i}}}{\left[F_{1}(T)-\rho_{\mathrm{i}} S_{\mathrm{i}} F_{2}(T)\right]}
$$

where $\rho_{\mathrm{i}}$ is the density of pure ice, $S_{\mathrm{i}}$ is the ice salinity in $\% o$ and $F_{1}(T)$ and $F_{2}(T)$ are two temperature-dependent constants derived from the phase relations (Assur, 1960). These relations have been specified for systems at atmospheric pressure; here, we are considering ice at water depths of approximately $150-200 \mathrm{~m}$. Correcting for the sea-water freezing-point depression, however, does not increase $V_{\mathrm{B}} / V$ by more than about $1 \%$ and has

Table 1. Approximate salinity, thickness and age of marine-ice layers and multi-year sea ice

\begin{tabular}{|c|c|c|c|c|}
\hline Location & $\begin{array}{c}\text { Salinity } \\
\%\end{array}$ & $\begin{array}{c}\text { Thickness } \\
\mathrm{m}\end{array}$ & $\begin{array}{l}\text { Age } \\
\text { years }\end{array}$ & Reference \\
\hline 1. Ronne Ice Shelf & $0.02-0.1$ & 170 & Hundreds & This work \\
\hline 2. Amery Ice Shelf & $0.05-0.1$ & 160 & Hundreds & Morgan (1972) \\
\hline 3. Hell's Gate Ice Shelf & $0.01-2$ & $35-80$ & Hundreds to thousands & $\begin{array}{l}\text { Baroni (1988); } \\
\text { Souchez and others (1991) }\end{array}$ \\
\hline 4. Ross Ice Shelf & $2-4$ & 6 & Hundreds & Zotikov and others (1980) \\
\hline 5. Koettlitz Ice Tongue & $0.2-5.3$ & $9-15$ & Tens & Gow and Epstein (1972) \\
\hline 6. Ward Hunt Ice Shelf & $0.3-15.3$ & 25 & Hundreds to thousands & Jeffries (1991) \\
\hline 7. Multi-year sea ice & $2-5$ & $2.5-5$ & Few years & Weeks and Ackley (1986) \\
\hline
\end{tabular}


consequently been disregarded. Based on stratigraphic analysis of the core and measured densities, the gas volume within the marine ice has been assumed to be zero in this case. Conversion of electrolytical conductivity measurements (Freier, 1974) may result in a systematic error, because these are based on $\mathrm{NaCl}$ being the only salt present in the solution. However, this error ranges far below the accuracy desired for the brine-volume assessment. The computed brine-volume distribution exhibits the same pattern as the electrolytical conductivity (Fig. 9 ). Due to higher temperatures at the bottom, a slight increase can be observed with depth. Most of the values fall within the fractional volume range of $0.09-0.2 \%$. This compares well with an estimate of $0.15 \%$ made by Moore and others (1994) based on SEM analysis of a sample from the very top of the marine-ice layer. If the salt content were to remain constant with depth, the fractional brine volume would increase to approximately $1 \%$ at the bottom of the ice shelf.

The brine salinity $S_{\mathrm{B}}$ within the ice can be also computed from the phase relations. Thus, near the bottom of the core with temperatures around $-9^{\circ} \mathrm{C}, S_{\mathrm{B}}$ is approximately $150 \%$ o but at the top of the marine layer $S_{\mathrm{B}}$ amounts to roughly $200 \%$. With these data at hand, we can compute the volume fraction of solid salts $V_{\mathrm{SS}} / V$, i.e. $\mathrm{NaSO}_{4} \cdot 10 \mathrm{H}_{2} \mathrm{O}$ and $\mathrm{CaCO}_{3} \cdot 6 \mathrm{H}_{2} \mathrm{O}$ (Assur, 1960), according to Cox and Weeks (1983)

$$
V_{\mathrm{SS}} / V=C(T)\left(\rho_{\mathrm{B}} / \rho_{\mathrm{SS}}\right)\left(V_{\mathrm{B}} / V\right)
$$

with $C(T)$ a temperature-dependent function, the density of solid salts $\rho_{\mathrm{SS}}$ assumed as $1500 \mathrm{~kg} \mathrm{~m}^{-3}$ and the density of brine $\rho_{\mathrm{B}}$ approximated as

$$
\rho_{\mathrm{B}}\left(\mathrm{kg} \mathrm{m}^{-3}\right)=1000+0.8 S_{\mathrm{B}}(\%) .
$$

Hence, the maximum relative volume of solid salts will be on the order of $0.01 \%$ at the top of the marine-ice layer (also depending to a small degree on the combined effects of hydrostatic pressure and temperature, which have been assumed to affect $V_{\mathrm{SS}}$ in the same way as the freezingpoint temperature and $S_{\mathrm{B}}$ ).

\subsection{Distribution of sediment layers within the marine ice}

Characteristically, the marine-ice layer contained abundant sediment inclusions, with maximum concentrations at depths between 152.8 and $159 \mathrm{~m}$. Detailed analysis of these inclusions shows the millimetre-sized pellets are aggregates of clay- and silt-fraction minerals and biogenic material (personal communication from R. Petschick, 1992). The inclusions are arranged into horizontal strings and layers (Fig. 10a). Sediment inclusions have also been reported from a core from the Amery Ice Shelf which has also been shown to be similar to the B13 core in many other respects (Wakahama, 1974). In order to obtain quantitative information on the spacing and width of these features, entire core sections of roughly $0.5 \mathrm{~m}$ length were recorded in transmitted light with the video system used for thin-section analysis. Subsequently, images were processed in such a way as to integrate the grey-value signals within horizontal layers, assigning layers devoid of inclusions a relative optical concentration of 0 and the

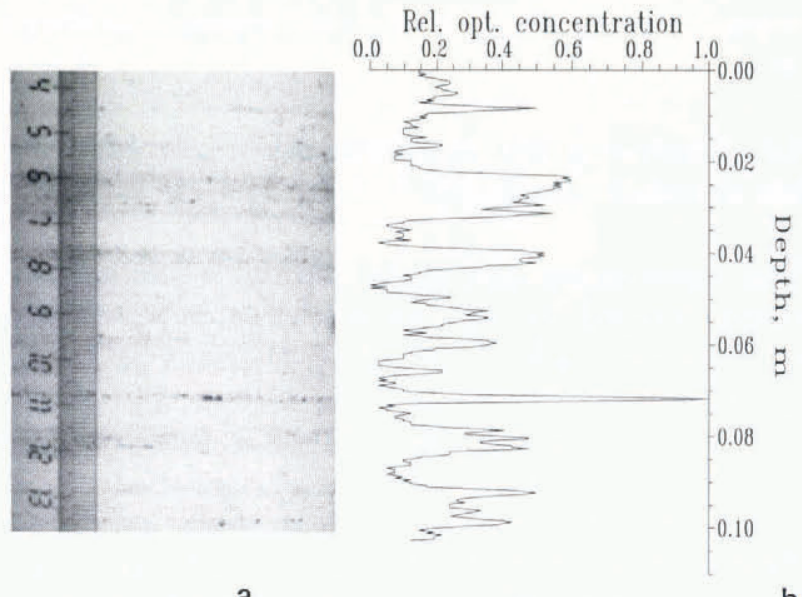

Fig. 10.a. Photograph of a vertical section of the core between 154.0 and $154.1 \mathrm{~m}$ depth (plain transmitted light). $b$. Relative concentration of microparticles based on integration of layer grey values over a depth range of $0.1 \mathrm{~m}$ (corresponding to the photograph shown in Figure 10a).

layer with absolute maximum impurity content a value of 1 (with a layer thickness of 0.3 and $1.2 \mathrm{~mm}$ depending on the chosen resolution; Fig. 10a). This allowed identification of horizons containing different amounts of particulate inclusions as shown for a $0.1 \mathrm{~m}$ section in Figure 10b. Whereas bulk concentrations of sediment within the ice are of the order of hundredths of grams per litre (personal communication from R. Petschick, 1992), peak values within such layers of $2-3 \mathrm{~mm}$ width are much higher.

Comparison of thin sections placed between crossed polarizers and in plain transmitted light confirms that inclusions are mostly confined to grain boundaries and triple junctions. Figure $10 \mathrm{~b}$ also indicates that the sediment layers do not occur at a consistent spacing or width. This has been verified by computing the autocorrelation function (acf) for the depth series of grey values recorded both at low and high resolution (layers of 1.2 and $0.3 \mathrm{~mm}$ width, respectively). None of the computed acfs provided any evidence of periodicity in the data. The correlation lengths, determined from the high-resolution images, amounted to a few millimetres at maximum ( $1.5 \mathrm{~mm}$ for the sample shown in Figure $10 \mathrm{~b}$ ).

\section{DISCUSSION: FORMATION AND TRANSFOR- MATION OF METEORIC AND MARINE ICE}

In order to learn more about the formation, flow and transformation of meteoric and marine ice in the central part of the Ronne Ice Shelf, we need to reconcile the key findings of this study, namely: (1) the observed grain-size $\left(A_{\text {mean }}\right)$ and grain-boundary density $\left(B_{\mathrm{A}}\right)$ profiles in the meteoric and in particular in the marine ice, where $B_{\mathrm{A}}$ decreases with depth (i.e. older ice being composed of smaller grains than younger ice); (2) the distribution of electrolytical conductivity or salinity with depth; and (3) the distribution of inclusions (brine and solid impurities) in relation to properties and history of the ice. This presupposes some knowledge of the deformation and 
thermal history of the ice column sampled at drilling site B13.

\subsection{Assessing the temperature-strain history of ice sampled at site B13}

The temperature and strain history of individual ice layers sampled in the core has been inferred from a particle-path model described by Thomas (1973). Here, the horizontal velocity of individual ice parcels is given by the ice-shelf velocity $v(x)$, while the vertical velocity component is determined by the accumulation rate $a$ at the ice surface and the vertical strain rate $\mathrm{d} \epsilon_{z} / \mathrm{d} t$. Temperatures within the ice shelf at different locations upstream of the drilling site have been linearly interpolated between the $10 \mathrm{~m}$ depth temperatures measured by Kipfstuhl and Oerter $\left(1991\right.$; roughly $\left.-25^{\circ} \mathrm{C}\right)$ and $-2^{\circ} \mathrm{C}$ at the ice-shelf bottom. Horizontal velocity components and vertical strain rates have been obtained from the measurements of Ritter and Karsten (1991) and Morris and Vaughan (1991), as well as from numerical model simulations by Determann (1991). Accumulation rates have been inferred from pit measurements (Graf and others, 1991, unpublished data).

Much less is known about the accumulation history of marine ice at the bottom of the ice shelf. In accordance with field measurements presented by Thyssen (1988) and numerical model simulations by Determann (1991) and Hellmer and Olbers (1991), we have assumed that accretion of marine ice takes place at a rate of $1.2 \mathrm{~m} \mathrm{a}^{-1}$ (ice) between 350 and $230 \mathrm{~km}$ upstream of the drilling location. For a further $180 \mathrm{~km}$ along the flowline, no net accumulation occurs. Melting sets in $50 \mathrm{~km}$ upstream of the drilling site $\mathrm{B} 13$ with melt rates increasing linearly from 0 to $5 \mathrm{~m} \mathrm{a}^{-1}$ (Determann, 1991). Based on the results presented in the next section, particle paths in the marineice layer have been approximated by linear functions.

\subsection{Comparison between observed grain-boundary densities and simulation results: meteoric ice layer}

The textural development of the meteoric ice sampled at different depths in the core is governed by the accumulation of strain due to ice-shelf flow and the minimization of free surface energy. The macroscopically prominent effects of the former process include wavy extinction, polygonization of grains and, finally, dynamic recrystallization (for a comprehensive discussion of the effects of stress and temperature on ice texture and fabric refer to: e.g. Budd and Jacka, 1989; Alley, 1992). Minimization of free surface energy is brought about by growth of grains associated with movement of high-angle grain boundaries (e.g. Gow, 1969; Paterson, 1981; Alley, 1992). For roughly isothermal firn and ice that has undergone negligible strain other than internal compaction, the resulting change in grain-size has been shown to obey an Arrhenius-type relationship (Gow, 1969). The combined effect of dynamic recrystallization and grain growth is at present not well understood. Here, we will first try to assess the potential influence of thermodynamic processes by computing grain growth for the variable temperature history of ice sampled at B13. As a second step, we will compare simulated and observed grain-sizes with respect to the strain history.

As shown by Gow (1969) for samples of Antarctic firn and ice under low or no deviatoric stress, growth of grains of initial cross-sectional area $A_{0}$ can be described by

$$
A=A_{0}+k t
$$

with a growth rate of $k\left(\mathrm{~mm}^{2} \mathrm{a}^{-1}\right)$ and a final crosssectional area $A$ at time $t$. The dependence of the growth rate $k$ on temperature $T$ is best described by

$$
k=k_{0} \exp (-Q / R T)
$$

$k_{0}$ being a constant, $R$ the universal gas constant of $8.314 \mathrm{~J} \mathrm{~mol}^{-1} \mathrm{~K}^{-1}, Q$ an activation energy and $T$ the temperature in $\mathrm{K}$. Thus, for a temperature history $T(t)$ derived from the particle-path model described in the previous section, we can compute $A$ at a time $t^{\prime}$ with an initial grain-size $A_{0}$ of $1 \mathrm{~mm}^{2}$ at time $t_{0}$ as observed in the upper firn layers, according to

$$
A=A_{0}+\int_{t_{0}}^{t^{\prime}} k_{0} \exp [-Q / R T(t)] \mathrm{d} t .
$$

Based on the polar-firn data compiled by Paterson (1981, p. 18), $Q$ is taken as $42.3 \mathrm{~kJ} \mathrm{~mol}^{-1}$ and $k_{0}$ as $8.3 \times$ $10^{6} \mathrm{~mm}^{2} \mathrm{a}^{-1}$.

Figure 8 presents the result of such a computation in combination with the data on meteoric ice obtained from the core. Note that grain-boundary density $B_{\mathrm{A}}$ has been derived from computed grain-sizes as well as those measured manually, assuming uniform grain crosssections of hexagonal (i.e. plane-filling) shape. While the computed curve reproduces the general trend of decreasing grain-boundary density with age, a closer inspection of measured and computed data indicates that, at least for the age span 300-1300 years, a computation based on grain growth overestimates $B_{\mathrm{A}}$, i.e. grain-sizes are larger than expected from thermodynamic growth alone. The growth rate, however, is reproduced fairly well up to an age of 1300 years, corresponding to a cumulative vertical strain $\left(\Delta z / z_{0}\right)$ of c. $70 \%$. Older ice exhibits little or no systematic change in $B_{\mathrm{A}}$ or $A_{\text {mean }}$. Sensitivity studies demonstrate that the observed age/grain-boundary density distribution is very little affected by fluctuations in ice velocities or accumulation rates, partly due to the counterbalance between the younger age of ice for higher velocities and accumulation rates, on the one hand, and enhanced grain growth due to faster burial of ice, on the other.

Comparatively little information is available on the combined effects of stress and thermodynamic processes on the grain-size of ice. Gow (1963) observed a roughly linear increase of grain cross-sectional area with depth in an ice core from the Ross Ice Shelf. In their study of a core from Byrd Station, Gow and Williamson (1976) reported increasing grain-sizes to a depth of about $600 \mathrm{~m}$, near-constant or decreasing grain-sizes from 600 to $1600 \mathrm{~m}$ depth and a further most distinct increase in the highly strained bottom $500 \mathrm{~m}$. For the Vostok core, Lipenkov and others (1989) observed an increase in grain-size with depth even in significantly strained ice (see also discussion by Alley (1992)). From this study, it appears that, irrespective of vertical strains up to $65 \%$, 
the grain-size profile is compatible with the thermal history of the ice. The observed $c$-axis distribution patterns (random up to a depth of roughly $40 \mathrm{~m}$ corresponding to $20 \%$ vertical strain and clustering into a vertical plane below) demonstrate the effects of basal glide in individual grains. Strain is accommodated locally through polygonization and sub-grain formation which are distinct below roughly $95 \mathrm{~m}$ depth in the core. While these processes result in a size decrease of a given grain population (and an increase in grain-boundary density), this effect is largely compensated by grain growth and dynamic recrystallization, as indicated by the complex, bulging grain shapes dominant in the lower half of the meteoric layer (Fig. 5a). At depths below about $120 \mathrm{~m}$ (corresponding to ages older than 1300 years and vertical strains $>65 \%$ ) grain-boundary densities assume nearconstant values around $0.7 \mathrm{~mm}^{-1}$ (grain-sizes of approximately $30 \mathrm{~mm}^{2}$ ). Such attainment of stationary grainsizes has been described by Jacka (1984) from laboratory experiments. He showed that, in the tertiary-creep regime at temperatures between $-7.1^{\circ}$ and $-10.6^{\circ} \mathrm{C}$, grain-sizes generally decrease (an increase was noted only for one set of very fine-grained samples) to an equilibrium size of roughly $2-2.5 \mathrm{~mm}$, i.e. far below the sizes encountered in the $\mathrm{B} 13$ core. As temperatures are lower by $10^{\circ}$ to $18^{\circ} \mathrm{C}$ in the Ronne Ice Shelf, it appears that low stresses are responsible for attainment of such large values of $A_{\text {stat }}$ in this case. Thus, for conditions representative of the Ronne Ice Shelf $\left(-20^{\circ} \mathrm{C}\right.$, octahedral shear stress of $0.05 \mathrm{MPa}$ and strain rate $\left.10^{-3} \mathrm{a}^{-1}\right)$, the compilation of data by Budd and Jacka (1989, fig. 10) indicates a stationary grain-size of $10 \mathrm{~mm}$ linear dimensions, i.e. the same magnitude as observed in the core (Fig. 3 ).

\subsection{Comparison between observed grain-boundary densities and simulation results: marine-ice layer}

The grain-boundary densities (Fig. 11) that have been computed for the marine-ice layer as outlined in section 4.1 demonstrate that the profiles change drastically during the no-accretion and ablation regimes. The simulation shows that grain-boundary densities increase with depth as long as ice is accumulated from below (i.e. grain-size proportional to age as generally observed in ice sheets). During the no-accretion and ablation stages, however, grain growth is favoured in the lower ice layers where temperatures are elevated. As a consequence, at the drilling location, the simulation shows $B_{\mathrm{A}}$ is constant with depth. Thus, longer residence times at higher temperatures are at least part of the explanation for the paradoxical observation of grain-sizes decreasing with age. However, the increasing values of $B_{\mathrm{A}}$ towards the top of the marine layer cannot be adequately explained by the simulation. Possibly, though unlikely as shown below, this increase towards the top could reflect differences in the initial size of the crystals accreting at the ice-shelf bottom.

Much more important with regard to grain growth are the insoluble, particulate inclusions ubiquitous in the upper layers. Several studies have dealt with the inhibition of grain growth owing to microparticle inclusions. Amongst others, Gow and Williamson (1976) found layers of volcanic ash coinciding with a drastic decrease in

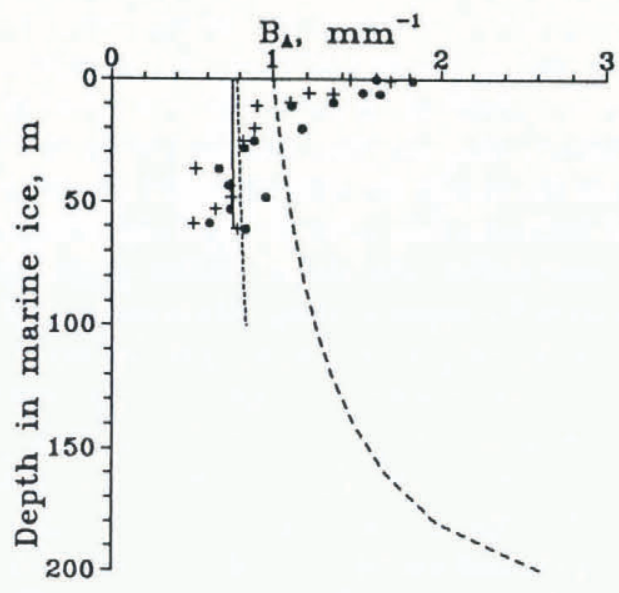

Computation, $\mathrm{km} 120$ Computation, $\mathrm{km} 300$ Computation, $\mathrm{km} 350$ - $B_{A}$, image-proc. data $+\mathrm{B}_{\Lambda}$, manual meas.

Fig. 11. Grain-boundary density profiles of the marine -ice layer ( $y$ axis shows depth below meteoric-marine-ice transition). Dots show automatically determined thinsection data, crosses are converted manual measurements of grain area. Dashed and solid lines demonstrate temporal development of profiles progressing through the zones of accumulation $(0-120 \mathrm{~km}$ away from the onset of accumulation; see also Fig. 1), zero accretion (120$300 \mathrm{~km})$ and ablation $(300-350 \mathrm{~km})$.

crystal size, attributed partly to the inhibitive effect of high microparticle concentrations. According to measurements made by Kyle and others (1982) on the Byrd Station core, particle concentrations in these dust layers are generally lower than those in the Ronne Ice Shelf (volume fractions in the range of $2 \times 10^{-7}$ with maxima near $5 \times 10^{-5}$ as compared to $10^{-3}$ to $5 \times 10^{-2} \mathrm{~g} \mathrm{I}^{-1}$; personal communication from R. Petschick). Alley and others (1986) developed a theory of grain growth in polar ice under low stress in the presence of microparticles. They derived an equation relating the ratio of the particle-drag force to the intrinsic (i.e. in the absence of solid impurities) driving force $P_{\mathrm{p}} / P_{\mathrm{i}}$ to volume $V_{\mathrm{p}}$ and radius $r_{\mathrm{p}}$ of particles

$$
P_{\mathrm{p}} / P_{\mathrm{i}}=9 V_{\mathrm{p}} R /\left(4 r_{\mathrm{p}}\right)
$$

for ice of average grain radius $R$. With mean particle sizes between 0.5 and $50 \mu \mathrm{m}$ and volume fractions between $10^{-5}$ and $10^{-4}$, and ice-grain radii around $5 \mathrm{~mm}, P_{\mathrm{p}} / P_{\mathrm{i}}$ takes on values between roughly $2 \times 10^{-3}$ and $2\left(P_{\mathrm{p}} / P_{\mathrm{i}}\right.$ describes the reduction in grain-growth rate as shown by Alley and others (1986)), indicating potentially mild to drastic retardation of grain growth for smaller particle sizes. Interpretation of computed ratios $P_{\mathrm{p}} / P_{\mathrm{i}}$ is complicated by the effects of (1) strain, which is not accounted for in theory; (2) coagulation of clay minerals during ageing resulting in particle-radius increase; (3) retainment of particles at triple-grain junctions, where they are of less influence on grain growth; and (4) enhanced concentrations of microparticles in grain-boundary zones. These limitations notwithstanding, the upper marine-ice layers should in theory experience restriction of grain growth. In practice, additional evidence is provided by 
the arrangement of elongated crystals into horizontal rows bounded by strings and layers of sediment, a feature which is not observed in the meteoric ice just above the discontinuity. Also, the predominance of the $0-2 \mathrm{~mm}$ size fraction in the marine ice with high solid impurity content (Fig. 6c) indicates that, even for small crystals with highly curved boundaries, the force driving grain growth is compensated by impurity drag. More important still, ice at roughly $70 \mathrm{~m}$ depth, within the meteoric layer, exhibits significantly lower grain-boundary densities than at the top of the marine-ice layer (see circled data points in Figure 3), even though the marine ice has experienced much higher temperatures favouring grain growth and dynamic recrystallization. Since the deformational history of these layers is comparable (meteoric ice at $70 \mathrm{~m}$ depth has been deposited near the point along the flowline where bottom accumulation sets in), we have to conclude that it is the solid impurity content that prevents more vigorous grain growth in the marine as compared to the meteoric ice. The concurrent increase in grain-boundary density and salinity towards the top of the marine ice might suggest a potential influence of salinity; yet, results from a second core taken in the Ronne Ice Shelf that is currently being processed, demonstrate that the sediment and not the salt is crucial in determining grain-size. In the second core, grain-sizes are observed to increase sharply (factor $>3$ ) as one passes from a zone of high silt content at $158.5 \mathrm{~m}$ depth to a layer that contains little or no sediment at $153.5 \mathrm{~m}$ at the very top of the marine-ice layer, while salinity does not vary significantly between the two. Similar observations have been made on the series of eight closely spaced thin sections from B13, where electrolytical conductivity measured on melted thinsection segments was not observed to correlate with grain-size. These findings are supported by laboratory experiments conducted by Achaval and others (1987) at temperatures between $-16^{\circ}$ and $-2^{\circ} \mathrm{C}$, who demonstrated that $\mathrm{NaCl}$ concentrations between $10^{-4}$ and $10^{-2} \mathrm{M}$ (0.006-0.6\%) enhance grain-growth rates. As will become clearer below, the explanation for a parallel trend in salinity and grain-boundary density may therefore lie in the early history of initial ice accretion underneath the ice shelf. Liquid impurities are also important in softening the basal ice layer, based on the observations made by Duval (1977), who measured an increase in shear rates of temperate ice by a factor of approximately 1.4 as the water content rose from nil to $0.05 \%$.

\subsection{Evolution of the salinity distribution and mechanisms of basal accretion}

One of the most telling pieces of evidence for the marine origin of the basal ice is the $\delta^{18} \mathrm{O}$ values, which increase from -40 to $+2 \%$ at the transition from meteoric to marine ice (Oerter and others, 1992). The latter value corresponds to that expected for equilibrium fractionation upon freezing of sea water circulating under the ice shelf. This does not explain the extraordinarily low salinity of the marine-ice layer which ranges roughly two orders of magnitude below values from sea ice or from basal ice underneath the Ross and Ward Hunt Ice Shelves. Anomalously low ice salinities may, in principle, be traced back to two potential causes: highly reduced incorporation of salt upon ice formation or vigorous loss of salt during later desalination. The wealth of research conducted within the sea-ice community allows us to assess the magnitude of either one of them (see Weeks and Ackley (1986) for a thorough review of this work).

The initial salinity $S_{\mathrm{i}}$ of an ice layer grown from sea water of salinity $S_{\mathrm{w}}$ is determined by an effective distribution coefficient $k_{\text {eff }}$ such that

$$
S_{\mathrm{i}}=k_{\mathrm{eff}} S_{\mathrm{w}} .
$$

From the experimental work of Lofgren and Weeks (1969), we obtain an estimate of $k_{\text {eff }}=0.15$ for growth velocities of approximately $3 \mathrm{~m} \mathrm{a}^{-1}$ for columnar sea ice (i.e. congelation of sea water at the ice-water interface). For slower growth rates, $k_{\text {eff }}$ approaches a minimum near 0.12 for sea ice (Weeks and Ackley, 1986). While ice grown from dilute salt solutions at very slow rates may incorporate much less salt during growth, this does not apply for the salinity and growth-rate regime encountered beneath the ice shelf where marine ice accretes with rates of decimetres to more than $1 \mathrm{~m} \mathrm{a}^{-1}$ (for constraints on accretion rates see section 4.1; Determann, 1991; Hellmer and Olbers, 1991). Other growth mechanisms, such as consolidation of frazil crystals, correspond to distribution coefficients larger or at best equal to those shown above because of similar or higher porosities of frazil as compared to ordinary congelation ice (see also Weeks and Ackley, 1986). Hence, the most conservative estimate of $k_{\text {eff }}=0.10$ yields an initial salinity of roughly $3.4 \%$ for the marine ice, i.e. more than two orders of magnitude above the actual values.

As a newly accreted layer of sea ice ages and cools due to additional growth below, a net export of salt occurs through a combination of three different brine-drainage mechanisms (Weeks and Ackley, 1986). One is the expulsion of brine upon cooling due to the differential decrease in porosity. Based on the equations of Cox and Weeks (1986), it can be shown that for the temperature gradients encountered in the marine-ice layer, brine explusion would lower the initial layer salinity by a factor of 0.85 at maximum (cooling from $-2^{\circ}$ to $-14^{\circ} \mathrm{C}$, as measured at the bottom of the B13 hole). This is still more than one order of magnitude higher than values found in the lower part of the core. Furthermore, whereas brine is easily expelled from sea ice through brine channels or cracks, it is not clear how brine could be expelled over vertical distances of several tens of metres through the marine ice column without any traces discernible in the core (neither in the two cores drilled in the Ronne Ice Shelf nor the one taken from the Amery Ice Shelf). As sea ice is cooled from the top, the density of brine increases upwards within an ice layer. In a process referred to as gravity drainage, the brine may be replaced by less-dense sea water, inducing a bulk-salinity decrease that is controlled by the local temperature gradient. The latter amounts to roughly $0.06^{\circ} \mathrm{C} \mathrm{m}^{-1}$, inducing a desalination rate of $0.3 \% \mathrm{a} \mathrm{a}^{-1}$ (Cox and Weeks, 1988). However, gravity drainage ceases once pores are not in hydraulic connection with the water column. For ordinary sea ice, this connection appears to be terminated at brine-volume fractions below 50\% (Cox and Weeks, 1988), implying that gravity drainage could only explain a decrease of marine-ice salinities to not less than $1.5 \%$. Finally, brine- 
filled pores migrate in a temperature gradient due to freezing at the cold and melting at the warm wall of the cavity. Based on the work by Hoekstra and others (1965) and Seidensticker (1966), maximum migration velocities should at maximum amount to roughly $2 \mathrm{~mm} \mathrm{a}^{-1}$ (at the bottom of the marine-ice layer).

Since the desalination rates resulting from any combination of these known desalination mechanisms are too low by at least two orders of magnitude, we are led to believe that the anomalously low salinities in the marine ice can only be explained by low initial salinities $S_{\mathrm{i}}$ of newly accreted ice layers. Based on the isotopic composition of the marine ice (indicating no incorporation of low-salinity glacial meltwater) and thermodynamic constraints (conductive heat flux in the central Ronne Ice Shelf on the order of $0.1 \mathrm{~W} \mathrm{~m}^{-2}$ ), we conclude that accretion of ice at the base takes place without significant in-situ ice growth. In addition, the accretion mechanism has to be associated with anomalously low salt-distribution coefficients ( $k_{\text {eff }}$ mostly $<0.001$ ), fundamentally different from those observed in ordinary sea ice. In view of the work of Kipfstuhl and others (1992), the mechanism in question is most likely associated with the accumulation of ice crystals beneath the ice shelf. Kipfstuhl and others have shown that ice crystals formed under water may constitute the marine-ice layers of Antarctic ice shelves. Such centimetre-sized ice platelets have been encountered at greater depths in front of the ice shelf by Dieckmann and others (1986) and are thought to accumulate in thick layers at the ice-shelf bottom. Indirect field evidence suggests an ice-water mixture is present at the base of the ice shelf, even though direct observations of this ice are still lacking to date (Engelhardt and Determann, 1987; Nicholls and others, 1991). In the absence of significant in-situ ice growth, these layers have to consolidate under the deviatoric buoyancy stress (c. $0.02 \mathrm{MPa}$ at the top of a $25 \mathrm{~m}$ crystal layer with an assumed $75 \%$ packing density) exerted by the tens of metres of crystals accumulating below. Densification and expulsion of brine would then take place through fragmentation and settling of platelets analogous to firn densification. Since ice platelets are essentially free of salt inclusions, brine only has to drain from intergranular boundaries. In addition, local uniaxial stress may cause impinging crystals to melt and recongeal within voids, with a corresponding decrease in brinevolume fractions (see LaChapelle (1968) for a discussion of the phenomenon).

\section{CONCLUSIONS}

A characteristic of the central part of the Ronne Ice Shelf is its complex, essentially two-fold structure, with an upper layer of meteoric ice underlain by marine ice. Even though deformation rates and total strain in the ice shelf are at the upper end of the scale typically found in ice sheets, our thin-section studies demonstrate that the meteoric ice texture compares quite well with cores from other sites. Grain-sizes increase roughly linearly up to a depth of roughly $120 \mathrm{~m}$, corresponding to cumulative strains of $65 \%$. Despite evidence of dynamic recrystallization and clustering of $c$ axes due to grain rotation away from the tensional axis, a simple particle-path thermalhistory model suggests that the observed grain-size profile is largely compatible with thermodynamically driven grain growth, at least to $120 \mathrm{~m}$ depth. Below, nearconstant grain-sizes around $30 \mathrm{~mm}^{2}$ are attained. A key factor in determining the magnitude of such a stationary grain-size, observed also in other localities, appears to be stress and strain rate, particularly when comparing field results with laboratory experiments (Jacka, 1984).

The texture of the marine-ice layer is characterized by a reversed age-grain-size relationship which can in part be explained by the thermal history of the ice. However, high concentrations of sediment inclusions, in particular in the top layers, were found to inhibit grain growth and recrystallization, in accordance with the model put forward by Alley and others (1986). If present in sufficient amounts, particulate inclusions can therefore be of great importance in determining the magnitude of stationary grain-sizes. The increase in grain-size with depth in the marine ice also has important implications for the effect of grain growth and dynamic recrystallization on grain-size. If the latter were important in this context, the observed distribution indicates that recrystallization in the Ronne Ice Shelf is as dependent on temperatures and content of liquid impurities (i.e. brine) as is grain growth. It might even be argued that the effects of dynamic recrystallization and grain growth on grainsize or grain-boundary density are inseparable as long as the stationary grain-size has not been attained.

Concentrations of salt inclusions in the marine ice range far below salt concentrations encountered in the Ward Hunt Ice Shelf, in marine ice below the Ross Ice Shelf and those found in sea ice. Since low salinities are not explicable through desalination processes, we conclude that it is the accretion process, envisaged as compaction and consolidation of a thick layer of loose crystals, which controls salinity in a way not previously described for other marine ice masses. In combination with other evidence, this finding implies that only during the growth of ice crystals freely suspended in the water column can we expect liberation of latent heat and salt into the surrounding water. At the site of compaction of these crystals, which may be greater distances from the site of initial ice growth, salt and heat fluxes should be minimal. Thus, increasing salinities toward the top of the marine-ice layer can be viewed as a result of enhanced accumulation rates toward the grounding line (as indicated by other investigations), which in combination with the distance to the grounding line may also explain the high sediment concentrations. Striking with regard to the texture and the distribution of solid and liquid impurities are the strong parallels between the Ronne Ice Shelf core and a core taken from the Amery Ice Shelf (Morgan, 1972; Wakahama, 1974). In particular, the close correspondence in observed grain-size distributions and the occurrence of particulate material suggests that the Amery Ice Shelf has a structure very much similar to that of the Ronne Ice Shelf. After this first small step, it now needs further work and, in particular, a closer look at the chemistry of the marine ice to arrive at a clearer picture of the evolution of the ice shelf and to understand the role of deformation, thermal history and impurity content in shaping its internal structure. 


\section{ACKNOWLEDGEMENTS}

We acknowledge financial support from the Deutsche Forschungsgemeinschaft. K.-H. Bässler, C. Drücker and W. Stadler are thanked for their help with drilling in the field. We thank F. Valero Delgado and U. Weigel for preparing and analyzing thin sections, R. Petschick for providing sedimentological data and S. Uratsuka for translating Japanese references. The comments of two anonymous reviewers, H. Hellmer, J. Moore and J.-L. Tison have been very helpful in improving this paper. This is Alfred-Wegener-Institut publication No. 634.

\section{REFERENCES}

Achaval, E. M. de, O. B. Nasello and E. A. Ceppi. 1987. Grain growth in laboratory prepared ice: solute effects. J. Phys. (Paris), 48, Collog. C1, 283-288. (Supplément au 3.)

Alley, R.B. 1988. Fabrics in polar ice sheets: development and prediction. Science, 240(4851), 493-495.

Alley, R. B. 1992. Flow-law hypotheses for ice-sheet modeling. F. Glaiol., 38(129), 245-256.

Alley, R. B. and C. R. Bentley. 1988. Ice-core analysis on the Siple Coast of West Antarctica. Ann. Glaciol., 11, 1-7.

Alley, R. B., J.H. Perepezko and C. R. Bentley. 1986. Grain growth in polar ice: I. Theory. 7. Glaciol., 32(112), 415-424.

Assur, A. 1960. Composition of sea ice and its tensile strength. SIPRE Res. Rep. 44.

Baroni, C. 1988. The Hells Gate and Backstairs Passage Ice Shelves, Victoria Land, Antarctica. Mem. Soc. Geol. It., 34, 123-144.

Blindow, N. 1990. Structures and dielectric properties of meteoric and marine ice in the central part of the Filchner Ronne Ice Shelf. In Miller, H., ed. Filchner-Ronne-Ice-Shelf-Programme. Report No. 4. Bremerhaven, Alfred Wegener Institute, 104-108.

Budd, W.F. and T. H. Jacka. 1989. A review of ice rheology for ice sheet modelling. Cold Reg. Sci. Technol., 16(2), 107-144.

Cox, G.F.N. and W.F. Weeks. 1983. Equations for determining the gas and brine volumes in sea-ice samples. 7. Glaciol., 29(102), 306-316.

Cox, G.F.N. and W.F. Weeks. 1986. Changes in the salinity and porosity of sea-ice samples during shipping and storage. F. Glaciol. 32(112), 371-375.

Cox, G.F.N. and W.F. Weeks. 1988. Numerical simulations of the profile properties of undeformed first-year sea ice during the growth season. J. Geophys. Res., 93(C10), 12,449-12,460.

Determann, J. 1991. Numerical modelling of ice shelf dynamics. Antarct. Sci., 3(2), 187-195.

Dieckmann, G. S., G. Rohardt, H. Hellmer and J. Kipfstuhl. 1986. The occurrence of ice platelets at $250 \mathrm{~m}$ depth near the Filchner Ice Shelf and its significance for sea ice biology. Deep-Sea Res., 33A(2), 141148.

Drewry, D.J. 1983. Antarctic ice sheet thickness and volume. In Drewry, D.J., ed. Antarctica: glaciological and geophysical folio. Cambridge, University of Cambridge. Scott Polar Research Institute, Sheet 4.

Duval, P. 1977. The role of the water content on the creep rate of polycrystalline ice. International Association of Hydrological Sciences Publication 118 (Symposium at Grenoble 1975-Isotopes and Impurities in Snow and Ice), 29-33.

Eicken, H. 1993. Automated image analysis of ice thin sectionsinstrumentation, methods and extraction of stereological and textural parameters. 7. Glaciol., 39(132), 341-352.

Engelhardt, H. and J. Determann. 1987. Borehole evidence for a thick layer of basal ice in the central Ronne Ice Shelf. Nature, 327(6120), 318-319.

Freier, R. K. 1974. Wasseranalyse. Berlin, Walter de Gruyter.

Fujita, S., M. Nakawo and S. Mae. 1987. Orientation of the 700-m Mizuho core and its strain history. Proceedings of the NIPR Symposium on Polar Meteorology and Glaciology 1, 122-131.

Gow, A.J. 1963. The inner structure of the Ross Ice Shelf at Little America V, Antarctica, as revealed by deep core drilling. International Association of Scientific Hydrology Publication 61 (General Assembly of Berkeley 1963-Snow and Ice), 272-284.

Gow, A.J. 1968. Deep core studies of the accumulation and densification of snow at Byrd Station and Little America V, Antarctica. CRREL Res. Rep. 197.

Gow, A.J. 1969. On the rates of growth of grains and crystals in south polar firn. J. Glaciol., 8(53), 241-252.

Gow, A. J. and S. Epstein. 1972. On the use of stable isotopes to trace the origins of ice in a floating ice tongue. J. Geophys. Res., 77(33), 65526557

Gow, A.J. and T. Williamson. 1976. Rheological implications of the internal structure and crystal fabrics of the West Antarctic ice sheet as revealed by deep core drilling at Byrd Station. CRREL Rep. 76-35.

Graf, W. and 6 others. 1991. Isotopic and chemical investigations of $10 \mathrm{~m}$ firn cores from the eastern part of the Ronne Ice Shelf, Antarctica. In Miller, H. and H. Oerter, eds. Filchner-Ronne-Ice-Shelf-Programme. Report No. 5. Bremerhaven, Alfred Wegener Institute, 45-53.

Hellmer, H. H. and D.J. Olbers. 1991. On the thermohaline circulation beneath the Filchner-Ronne ice shelves. Antarct. Sci., 3(4), 433-442.

Hoekstra, P., T. E. Osterkamp and W.F. Weeks. 1965. The migration of liquid inclusions in single ice crystals. F. Geophys. Res., 70(20), 50355041 .

Jacka, T.H. 1984. Laboratory studies on relationships between ice crystal size and flow rate. Cold Reg. Sci. Technol., 10(1), 31-42.

Jeffries, M.O. 1991. Massive, ancient sea-ice strata and preserved physical-structural characteristics in the Ward Hunt Ice Shelf. Ann. Glaciol., 15, 125-131.

Jenkins, A. and C. S. M. Doake. 1991. Ice-ocean interaction on Ronne Ice Shelf, Antarctica. 7. Geophys. Res., 96(C1), 791-813.

Kipfstuhl, J. and H. Oerter. 1991. Feldglaziologische Arbeiten. Ber. Polarforsch. 86, 69-71.

Kipfstuhl, J., G. Dieckmann, H. Oerter, H. Hellmer and W. Graf. 1992. The origin of green icebergs in Antarctica. 7. Geophys. Res., 97(C12), 20,319-20,324.

Kyle, P., J. Palais and R. Delmas. 1982. The volcanic record of Antarctic ice cores: preliminary results and potential for future investigations. Ann. Glaciol., 3, 172-177.

LaChapelle, E. 1968. Stress-generated ice crystals in a nearly isothermal two-phase system. F. Glaciol., 7(50), 183-198.

Lipenkov, Y.Ya., N.I. Barkov, P. Duval and P. Pimienta. 1989. Crystalline texture of the $2083 \mathrm{~m}$ ice core at Vostok Station, Antarctica. 7. Glaciol., 35(121), 392-398.

Lofgren, G. and W.F. Weeks. 1969. Effect of growth parameters on substructure spacing in $\mathrm{NaCl}$ ice crystals. 7. Glaciol., 8(52), 153-164.

Moore, J. C., A.P. Reid and J. Kipfstuhl. 1994. Microstructure and electrical properties of marine ice and its relationship to meteoric ice and sea ice. 7. Geophys. Res., 99(C3), 5171-5180.

Morgan, V. I. 1972. Oxygen isotope evidence for bottom freezing on the Amery Ice Shelf. Nature, 238(5364), 393-394.

Morris, E. M. and D. G. Vaughan. 1991. Glaciological measurements on the South Ronne Ice Shelf. In Miller, H. and H. Oerter, eds. FilchnerRonne-Ice-Shelf-Programme. Report No. 5. Bremerhaven, Alfred Wegener Institute, 37-44.

Nicholls, K.W., K. Makinson and A.V. Robinson. 1991. Ocean circulation beneath the Ronne Ice Shelf. Nature, 354(6350), 221-223.

Oerter, H. and 6 others. 1992. Evidence for basal marine ice in the Filchner-Ronne Ice Shelf. Nature, 358(6385), 399- 401.

Paterson, W.S.B. 1981. The physics of glaciers. Second edition. Oxford, etc., Pergamon Press.

Ritter, B. and A. Karsten. 1991. Geodäsie. Ber. Polarforsch. 86, 50-57.

Seidensticker, R. G. 1966. Comment on paper by P. Hoekstra, T. E. Osterkamp and W.F. Weeks, "The migration of liquid inclusions in single ice crystals". J. Geophys. Res., 71(8), 2180-2181.

Souchez, R. and 8 others. 1991. Ice composition evidence of marine ice transfer along the bottom of a small Antarctic ice shelf. Geophys. Res. Lett., 18(5), 849-852.

Thomas, R.H. 1973. The dynamics of the Brunt Ice Shelf, Coats Land, Antarctica. Br. Antarct. Surv. Sci. Rep. 79.

Thyssen, F. 1988. Special aspects of the central part of Filchner-Ronne Ice Shelf, Antarctica. Ann. Glaciol., 11, 173-179.

Vaughan, D. G., C. S. M. Doake and D. R. Mantripp. 1991. Thematic maps of Filchner-Ronne Ice Shelf. In Miller, H. and H. Oerter, eds. Filchner-Ronne-Ice-Shelf-Programme. Report No. 5. Bremerhaven, Alfred Wegener Institute, 8-11.

Wakahama, G. 1974. Structures and textures of the Amery Ice Shelf, Wilkes Ice Cap and Cape Folger, Antarctica. In Japanese Science Foundation, ed. Physical and chemical studies of ice from glaciers and ice sheets. Tokyo, Japanese Science Foundation, 99-108. [In Japanese.]

Weeks, W.F. and S.F. Ackley. 1986. The growth, structure, and properties of sea ice. In Untersteiner, N., ed. The geophysics of sea ice. Dordrecht, Martinus Nijhoff Publ., 9-164. (NATO ASI Ser., Ser. B, 146.)

Zotikov, I.A., V.S. Zagorodnov and J. V. Raikovsky. 1980. Core drilling through the Ross Ice Shelf (Antarctica) confirmed basal freezing. Science, 207(4438), 1463-1465.

The accuracy of references in the text and in this list is the responsibility of the authors, to whom queries should be addressed. 